\title{
Tingkat Bahaya Bencana Banjir di Kali Lamong Kabupaten Gresik
}

\author{
Maulidya Aghysta Fristyananda dan Hertiari Idajati \\ Jurusan Perencanaan Wilayah dan Kota, Fakultas Teknik Sipil dan Perencanaan, \\ Institut Teknologi Sepuluh Nopember (ITS) \\ Jl. Arief Rahman Hakim, Surabaya 60111 Indonesia \\ e-mail: hertiari_idajati@urplan.its.ac.id
}

\begin{abstract}
Abstrak-Adanya Daerah Aliran Sungai (DAS) Kali Lamong tidak terlepas dari berbagai macam pemanfaatannya. Salah satunya pemanfaatan area hijau DAS Kali Lamong di Kabupaten Gresik, sebagai kawasan budidaya yang menyebabkan kemerosotan lingkungan dan memicu terjadinya banjir. Pada tahun 2015, banjir Kali Lamong memberikan dampak terhadap setidaknya 9.587 jiwa dan 3 orang meninggal dunia serta kerugian materiil mencapai Rp 18 Milyar. Penelitian ini bertujuan untuk mengidentifikasi tingkat bahaya bencana banjir yang terjadi di sepanjang kali lamong. Artikel ini merupakan bagian dari penelitian Arahan Peningkatan Kapasitas Masyarakat di Kawasan Rawan Bencana Banjir Kali Lamong, Kabupaten Gresik. Pemetaan klasifikasi tingkat Bahaya banjir Kali Lamong di Kabupaten Gresik dilakukan berdasarkan karakteristik banjir dengan alat analisis menggunakan teknik analisis Overlay Weighted Sum dan pembobotan menggunakan AHP. Hasil yang diperoleh dari penelitian ini adalah terdapat 10 desa dengan tingkat bahaya banjir tinggi, 31 desa dengan tingkat bahaya sedang dan 13 desa dengan tingkat bahaya rendah. Hasil penelitian ini merupakan salah satu tahapan untuk mengetahui tingkat resiko bencana banjir di Kawasan Kali Lamong.
\end{abstract}

Kata Kunci-Karakteristik banjir, Overlay Weighted Sum, tingkat bahaya

\section{PENDAHULUAN}

B ANJIR adalah meluapnya aliran sungai akibat air melebihi kapasitas tampungan sungai sehingga meluap dan menggenangi dataran atau daerah yang lebih rendah di sekitarnya [1]. Banjir menjadi sebuah ancaman apabila dataran rawan banjir telah dikembangkan menjadi kawasan dengan aktivitas permukiman, perkotaan, pertanian, dan kawasan peruntukan lainnya. Salah satu wilayah dengan dampak banjir cukup besar adalah Kabupaten Gresik yang dilewati oleh dua sungai besar, yakni Bengawan Solo dan Kali Lamong. Kali Lamong bermuara di Selat Madura dengan panjang sungai 54 Km yang melewati 5 kecamatan di Kabupaten Gresik, antara lain Kecamatan Benjeng, Kecamatan Menganti, Kecamatan Kedamean, Kecamatan Cerme, dan Kecamatan Balongpanggang [2].

Kali Lamong mulai mengalami kemerosotan kualitas lingkungan yang menyebabkan ancaman banjir. Hal tersebut terlihat dari permasalahan Daerah Pengaliran Sungai (DPS) Kali Lamong yang pada musim kemarau memiliki debit sebesar $250 \mathrm{~m}^{3} /$ detik, sedangkan debit di musim penghujan sebesar $700 \mathrm{~m}^{3} /$ detik. Selain permasalahan DPS, luasan area penghijauan di DAS Kali Lamong berkurang akibat adanya pengembangan kawasan budidaya. Banjir yang bersumber dari Kali Lamong meluap hingga ke jaringan jalan arteri yang menghubungkan Kabupaten Gresik, Kabupaten Lamongan, Kabupaten Mojokerto, dan Kota Surabaya sehingga mengganggu arus lalu lintas. Secara topografis, badan Sungai Kali Lamong di Kabupaten Gresik terbilang landai. Sehingga, apabila terjadi hujan deras atau air laut mengalami kondisi pasang, permukaan air akan melebihi bibir sungai yang menyebabkan terjadinya banjir. Selain itu, juga terjadi pendangkalan di kanan dan di kiri sungai yang diperparah dengan tidak adanya tanggul sepanjang $7 \mathrm{~km}$ dari wilayah Kecamatan Benjeng hingga Kecamatan Cerme [3].

Pada Februari 2015, banjir setinggi 30-100 cm merendam 1.245 rumah di Kecamatan Benjeng, 655 rumah di Kecamatan Cerme, dan 581 rumah di Kecamatan Menganti. Masyarakat terdampak akibat banjir tersebut adalah sekitar 9.587 jiwa dan 3 (tiga) orang meninggal dunia.[4]. Kerugian materiil secara keseluruhan diperkirakan mencapai angka Rp 18 Miliar, dengan terendamnya $3.000 \mathrm{Ha}$ lahan pertanian dan $378 \mathrm{Ha}$ diantaranya dinyatakan gagal panen [5]. Selain kerugian materiil, banjir merendam sekolah-sekolah yang mengakibatkan kegiatan belajar mengajar berhenti secara total dan mengganggu aksesibilitas sehingga masyarakat kesulitan mendapatkan air bersih dan makanan [6].

Sehingga pemetaan tingkat bahaya perlu dilakukan agar dapat mengurangi tingkat resiko bencana banjir di kawasan kali lamong.

\section{METODE PENELITIAN}

\section{A. Metode Pengumpulan Data}

Metode pengumpulan data yang dilakukan pada penelitian ini adalah teknik survey primer dan sekunder. Survey primer dilakukan dengan wawancara semi terstruktur kepada stakeholder terpilih yaitu BPBD Kabupaten Gresik dan Perwakilan Camat Cerme, Benjeng, Menganti, Balungpanggang dan Kedamean. Sedangkan survei sekunder dilakukan dengan survei instansional untuk memperolah gambaran umum wilayah penelitian.

\section{B. Metode Analisis}

Pada analisis ini terdapat dua tahapan utama yaitu mengetahui tingkat bahaya banjir berdasarkan karakteristik 
bahaya banjir dan mengetahui daerah dengan tingkat bahaya dan kerentanan tinggi. Metode analisis yang digunakan adalah menggunakan Overlay Weighted Sum yang dilakukan untuk memetakan kawasan dengan komponen karakteristik banjir menggunakan alat analisis ArcGIS. Overlay Weighted Sum adalah teknik analisis spasial dengan melakukan tumpang tindih pada peta untuk menghasilkan suatu peta baru dengan menggunakan pembobotan pada tiap input peta. Pembobotan dilakukan menggunakan teknik Analytical Hierarchy Process (AHP). Teknik AHP dilakukan untuk mendapatkan nilai bobot pada setiap variabel karakteristik bahaya banjir. Pembobotan bertujuan untuk menuntukan prioritas variabel yang berpengaruh terhadap tingkat bahaya banjir.

\section{HASIL DAN PEMBAHASAN}

\section{A. Analisis AHP}

Tingkat bahaya banjir dilihat berdasarkan karakteristik banjir yang terjadi di Kali Lamong Kabupaten Gresik.Dalam melakukan proses analisis, perlu dilakukan pembobotan pada tiap variabel untuk mempengaruhi besaran pengaruh tiap variabel. Pembobotan dilakukan menggunakan alat analisis AHP dengan software Expert Choice 11. Pada pembobotan antar variabel bahaya, variabel yang digunakan adalah luas genangan, lama genangan, dan kedalaman genangan. Berikut ini merupakan hasil pembobotan melalui AHP pada sub variabel luas genangan banjir:

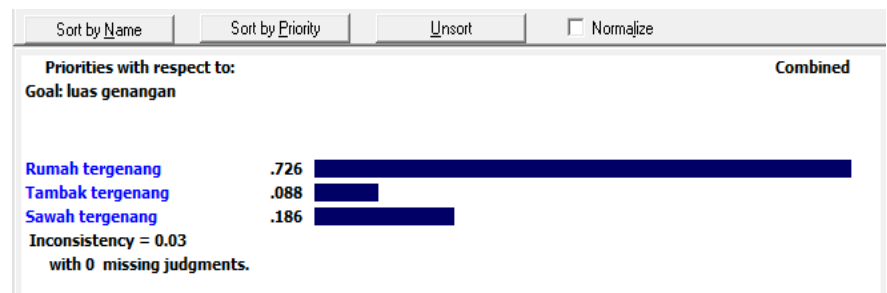

Gambar 1. Hasil AHP Pembobotan Antar Sub Variabel Luas Genangan Sumber : Hasil Analisis, 2016

Sub variabel yang digunakan dalam pembobotan variabel luas genangan adalah rumah tergenang (unit), tambak tergenang (Ha), dan sawah tergenang (Ha). Berdasarkan hasil pembobotan, didapatkan bahwa subvariabel yang menjadi prioritas utama dalam variabel luas genangan adalah jummlah rumah masyarakat yang tergenang banjir. Nilai Inconsistency pada pembobotan sub variabel luas genangan adalah 0.03 sehingga hasil pembobotan dapat dikatakan konsisten. Bobot yang dihasilkan dari AHP adalah sebagai berikut: a. Bobot rumah tergenang sebesar 0.726. Hal ini menunjukkan bahwa sub rumah tergenang merupakan prioritas pertama dalam variabel luas genangan

b. Bobot sawah tergenang sebesar 0.186. Hal ini menunjukkan bahwa sub sawah tergenang merupakan prioritas kedua dalam variabel luas genangan

Bobot tambak tergenang sebesar 0.088. Hal ini menunjukkan bahwa sub variabel tambak tergenang merupakan prioritas ketiga dalam variabel luas genangan.

Berikut ini merupakan hasil pembobotan indikator tingkat bahaya bencana banjir melalui alat analisis AHP:

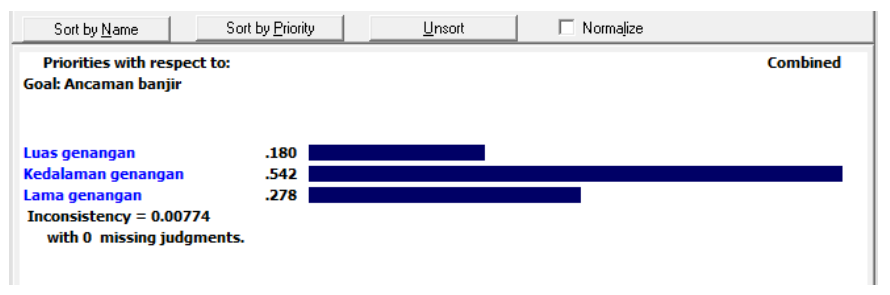

Gambar 2. Hasil AHP Pembobotan Variabel Bahaya Banjir Berdasarkan Karakteristiknya

Sumber : Hasil Analisis, 2016

Berdasarkan hasil pembobotan melalui AHP, didapatkan bahwa variabel kedalaman genangan merupakan prioritas utama dengan bobot 0.542. Nilai Inconsistency pada pembobotan indikator bahaya banjir adalah 0.00774 sehingga dapat dikatakan bahwa hasil pembobotan tersebut konsisten. Berikut ini adalah masing-masing pembobotan menggunakan alat analisis AHP:

a. Bobot kedalaman genangan sebesar 0.542. Hal ini dapat diartikan bahwa variabel kedalaman genangan merupakan proritas pertama dalam indikator bahaya bencana banjir

b. Bobot lama genangan sebesar 0.278. Hal ini dapat diartikan bahwa variabel kedalaman genangan merupakan prioritas kedua dalam indikator bahaya bencana banjir.

c. Bobot luas genangan sebesar 0.180. Hal ini dapat diartikan bahwa variabel luas genangan merupakan prioritas ketiga dalam indikator bahaya bencana banjir.

\section{B. Mengetahui Tingkat Bahaya Banjir Kali Lamong}

Untuk mengetahui tingkat bahaya banjir Kali Lamong dilakukan pembobotan terhadap klasifikasi banjir yang meliputi kedalaman banjir, lama genangan, rumah tergenang, tambak tergenang dan sawah tergenang. Untuk pembagian klasifikasinya dapat dilihat pada tabel dibawah ini.

Tabel 1.

Klasifikasi Variabel Karakteristik Banjir

\begin{tabular}{clll}
\hline \hline No. & \multicolumn{1}{c}{ Proses Klasifikasi } & \multicolumn{1}{c}{ Pembagian Klasifikasi } \\
\hline 1 & Kedalaman Banjir & Rendah $:$ skor $<0.33(1-29,7 \mathrm{~cm})$ \\
& $\frac{\text { nilai maksimal kelas }}{\text { total skor }=1} x$ kedalaman banjir maksimal & $\bullet$ Sedang $:$ skor $0.34-0.66(29,8-59,4 \mathrm{~cm})$ \\
& $\frac{0.33}{1} \times 90 \mathrm{~cm}=29,7 \mathrm{~cm}$ & & \\
\hline \hline
\end{tabular}




\begin{tabular}{|c|c|c|}
\hline No. & Proses Klasifikasi & Pembagian Klasifikasi \\
\hline 2 & $\begin{array}{l}\text { Lama Genangan } \\
\frac{\text { nilai maksimal kelas }}{\text { total skor }=1} \times \text { lama banjir maksimal } \\
\frac{0.33}{1} \times 7 \text { hari }=2 \text { hari }\end{array}$ & 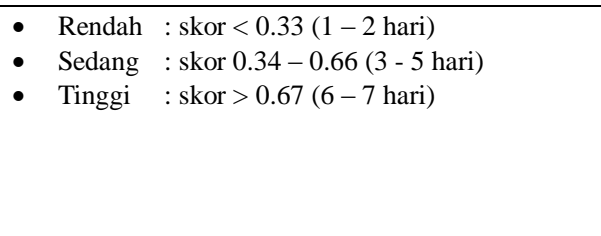 \\
\hline 3 & $\begin{array}{l}\text { Rumah Tergenang } \\
\frac{\text { nilai maksimal kelas }}{\text { total skor }=1} \times \text { jumlah rumah paling banyak } \\
\frac{0.33}{1} \times 700 \text { rumah }=231 \text { rumah }\end{array}$ & 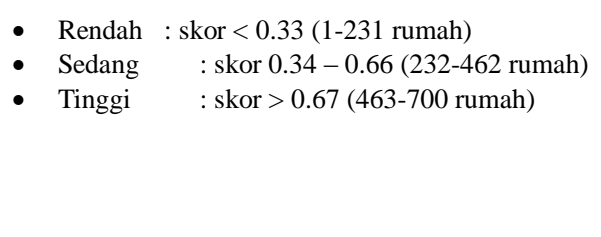 \\
\hline 4 & $\begin{array}{l}\text { Tambak Tergenang } \\
\frac{\text { nilai maksimal kelas }}{\text { total skor }=1} x \text { luasan maksimal tambak tergenang } \\
\frac{0.33}{1} \times 150 \mathrm{Ha}=49,5 \mathrm{Ha}\end{array}$ & $\begin{array}{llc}\text { - } & \text { Rendah } & \text { : skor }<0.33(1-49,5 \mathrm{Ha} \\
\text { - } & \text { Sedang } & : \text { skor } 0.34-0.66(49,6-99 \mathrm{Ha}) \\
\text { - } & \text { Tinggi } \quad: \text { skor }>0.67(99,1-150 \mathrm{Ha})\end{array}$ \\
\hline 5 & $\begin{array}{l}\text { Sawah Tergenang } \\
\frac{\text { nilai maksimal kelas }}{\text { total skor }=1} \times \text { luasan maksimal sawah tergenang } \\
\frac{0.33}{1} \times 205 \mathrm{Ha}=67,69 \mathrm{Ha}\end{array}$ & $\begin{array}{lll}\text { - } & \text { Rendah } & \text { : skor }<0.33(1-67,69 \mathrm{Ha}) \\
\text { - } & \text { Sedang } \quad: \text { skor } 0.34-0.66(67,7-135,3 \mathrm{Ha}) \\
\text { - } & \text { Tinggi } \quad: \text { skor }>0.67(135,5-205 \mathrm{Ha})\end{array}$ \\
\hline
\end{tabular}

Sumber: Hasil Analisis, 2016

Zona tingkat bahaya atau bahaya banjir yang dilakukan adalah tingkat bahaya atau bahaya banjir di kawasan penelitian, yakni banjir Kali Lamong Kabupaten Gresik. Zona tingkat bahaya banjir pada kawasan penelitian dizonasikan ke dalam tiga zona, yakni zona bahaya rendah, zona bahaya sedang, dan zona bahaya tinggi. Zonasi bahaya didapatkan dari hasil overlay variabel area tergenang, kedalaman genangan, dan lama genangan menggunakan teknik Overlay Weighted Sum. Berikut ini merupakan tahapan dari analisis zona tingkat bahaya banjir.

Berikut ini merupakan tahapan dalam melakukan zonasi tingkat ancaman bencana banjir secara keseluruhan:

1. Tahap input data

Pada tahap ini data mengenai variabel bahaya banjir dimasukkan ke dalam software ArcGIS 10.1 untuk diintepretasikan dalam bentuk peta. Sehingga data dapat disajikan dalam bentuk spasial yang nantinya akan diklasifikasikan menjadi tiga kelas.

2. Tahap pengolahan data

Pada tahap pengolahan data, langkah yang dilakukan adalah mengkonversi peta dengan jenis polygon menjadi raster (Polygon to raster). Setelah dilakukan konversi menjadi data raster, tahap selanjutnya adalah melakukan Reclassify tiap variabel ke dalam 3 kelas, yakni skala rendah (skala 1), sedang (skala 2), dan tinggi (skala 3 ).

3. Tahap overlay data

Pada tahap ini, dilakukan overlay data mengenai variabel bahaya bencana banjir menggunakan alat analisis Overlay
Weighted Sum pada ArcGIS 10.1. pada proses overlay digunakan pembobotan yang merupakan hasil dari analisis AHP mengenai variabel bahaya bencana banjir.

Dapat dikatakan bahwa semakin banyak area tergenang yang menggenangi suatu wilayah dan semakin tinggi suatu wilayah tergenang maka semakin tinggi pula tingkat bahaya yang ada pada wilayah tersebut. Hal tersebut juga mempengaruhi pada dampak yang didapatkan dari adanya banjir. Selain itu, semakin lama air menggenangi suatu wilayah terdampak banjir, maka semakin lama pula katifitas masyarajat yang terganggu. Berdasarkan hasil analisis overlay, didapatkan tiga klasifikasi dengan skor sebagai berikut:

a. Tingkat bahaya rendah : $0-0.934$

b. Tingkat bahaya sedang : $0.934-1.869$

c. Tingkat bahaya tinggi : $1.869-2.802$

Desa yang memiliki tingkat bahaya banjir tinggi terdapat pada tiga kecamatan, yakni:

1. Kecamatan Cerme : Desa Morowudi dan Iker-iker Geger

2. Kecamatan Benjeng : Desa Lundo, Bulangkulon, Balongmojo, Gluranploso, dan Bulurejo

3. Kecamatan Menganti : Desa Boboh, Gadingwatu, dan Beton.

Hasil analisis overlay disajikan dalam bentuk peta pada Peta Klasifikasi Tingkat Bahaya Bencana Banjir Kali Lamong Kabupaten Gresik. 


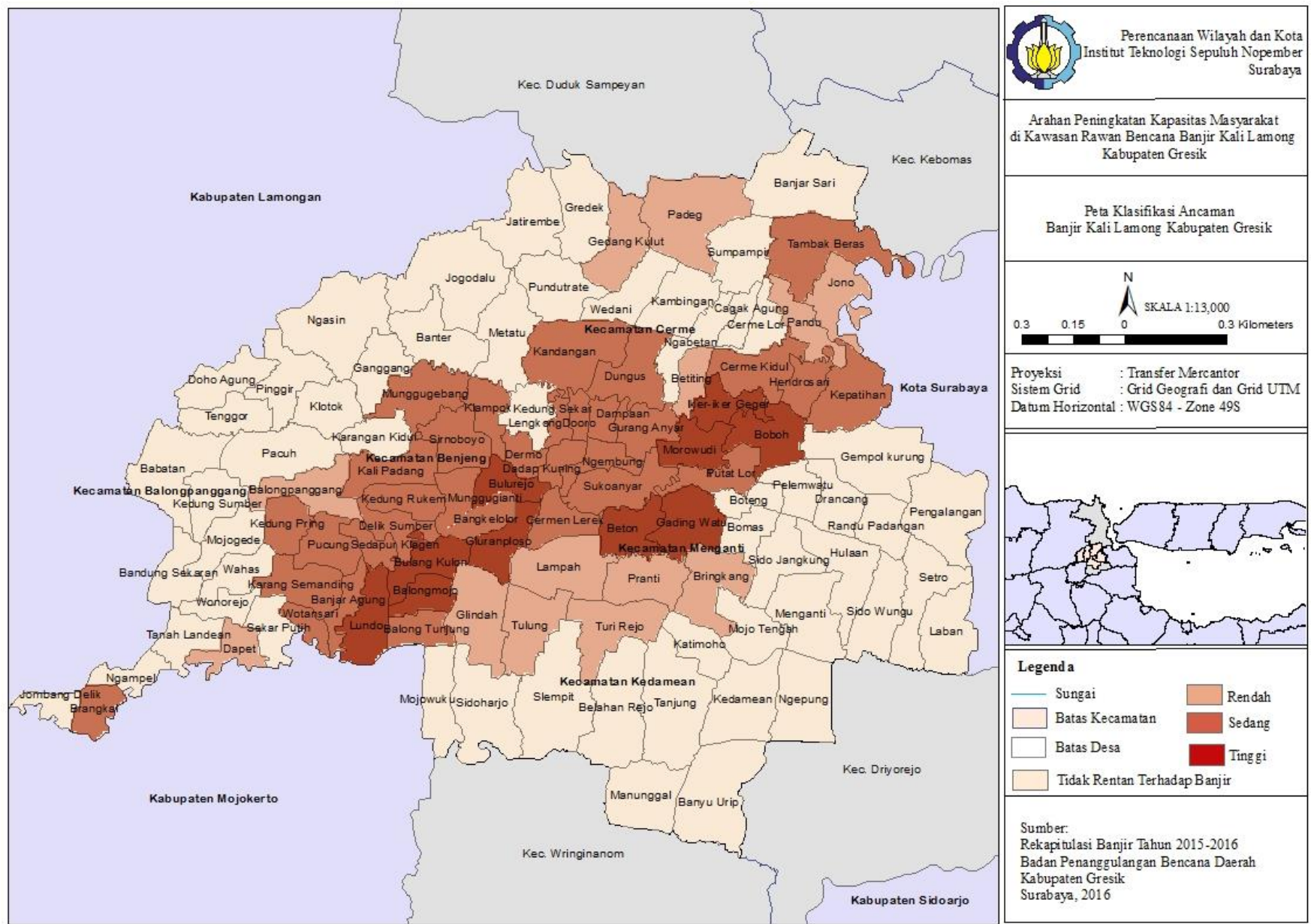

Gambar 3 Peta Klasifikasi Bahaya Banjir Kali Lamong Kabupaten Gresik

Sumber: Hasil Analisis, 2016

\section{KESIMPULAN}

Berdasarkan hasil analisis dan pembahasan yang dilakukan dalam penelitian, didapatkan hasil sebagai berikut:

1. Data karakteristik banjir yang digunakan dalam pemetaan tingkat bahaya banjir adalah luas genangan, lama genangan, dan kedalaman genangan.

2. Jumlah desa terdampak pada banjir Kali Lamong di Kabupaten Gresik sebesar 54 desa yang termasuk ke dalam 3 kecamatan, yakni Kecamatan Benjeng, Cerme, dan Menganti.

3. Terdapat sepuluh desa yang memiliki tingkat bahaya banjir tinggi berdasarkan karakteristiknya, yakni Desa Morowudi, Iker-iker Geger, Lundo, Bulangkulon, Balongmojo, Gluranploso, Bulurejo, Boboh, Gadingwatu, dan Beton.

4. Terdapat 31 desa yang memiliki tingkat bahaya banjir sedang, yakni Desa Tambak Beras, Kepatihan, Hendrosari, Cerme Kidul, Putatlor, Sukoanyar, Ngembung, Gurang anyar, Dampaan, Dungus, Kandangan, Kedung sekar, Dooro, Dermo, Dadap Kuning, Cermen lerek, Munggugebang, Klampok, Sirnoboyo, Munggugianti, Bangkelolor, Kedungrukem, Delik sumber, sedapur klagen, Pucung, Kedungpring,
Brangkal, Wotansari, Banjaragung, Karang semanding, dan Balong Tunjung.

5. Terdapat 13 desa yang memiliki tingkat bahaya banjir rendah, yakni Desa Padeg, Gedang Kulut, Jono, Pandu, betiting, Balongpanggang, Lampah, Glindah, Tulung, Turirejo, Pranti, Beringkang, dan Dapet.

\section{DAFTAR PUSTAKA}

[1] Syihab, Usman., dan Yulaelawati, Ella. (2008). Mencerdasi Bencana. Jakarta: Grasindo

[2] RTRW Kabupaten Gresik Tahun Anggaran 2004-2014

[3] Santoso, Eko Budi. (2013). Jurnal Penataan Ruang Volume 8: Manajemen Risiko Bencana Banjir Kali Lamong Pada Kawasan Peri Urban Surabaya-Gresik Melalui Pendekatan Kelembagaan. Surabaya

[4] Rekapitulasi Banjir Kali Lamong Tahun 2015 BPBD Kabupaten Gresik Tahun 2015

[5] Ibrahim, Malik (9 Februari 2015). Antara News Jawa Timur. http://www.antarajatim.com/berita/151343/bpbd--kerugian-banjir-gresikcapai-rp18-miliar diakses 29 Oktober 2015

[6] Indosiar (Februari 2015). Indosiar Visual Mandiri. http://www.indosiar.com/fokus/banjir-di-gresik-resahkan-petanitambak_27055.html diakses 29 Oktober 2015 